\title{
Results of 10 years sampling of Chironomidae from German lowland running waters differing in degradation
}

\author{
Claus ORENDT* \\ WaterBioAssessment, Brandvorwerkstraße 66, 04275 Leipzig, Germany \\ *Corresponding author: orendt@hydro-bio.de
}

\begin{abstract}
Based on data from monitoring in north-east Germany (Land Brandenburg) over a decade, chironomid taxa and their abundances were analysed for their preferences for certain running water types and degradation levels. A detrended correspondence analysis (DCA) revealed that the distribution of the taxa was determined by both, degradation level and water body type. A series of taxa was positively or negatively correlated to degradation, however, frequently only in certain water body types. In other types, they played no major role or were evenly distributed along the degradation gradient. Higher correlations were found for taxa favouring 'good' and 'poor' or 'bad' conditions than for preferers of 'moderate' status. The results allow to validate indices and weights of indicators derived from high frequencies of the taxa in certain one or more quality class(es). The preferred occurrences elaborated have to be discussed or tested for plausibility before using or evaluating powerful indicator taxa for classifications or revisions in assessment practice. A reduction of the taxonomical precision to genus level lowered the statistical significance and requires careful examination of the species preferences of the genus respected.
\end{abstract}

Key words: Community; degradation gradient; water types, DCA; Brandenburg.

Received: February 2018. Accepted: July 2018.

This paper was presented at the $20^{\text {th }}$ International Symposium on Chironomidae, Trento, Italy, 2-8 July 2017. Session: Ecology and Biomonitoring.

\section{INTRODUCTION}

The implementation of the European Water Framework Directive (European Commission, 2000) requires a big number of samples of water organisms for monitoring the ecological states of water bodies of concern. Many data of the distributions and indication values of aquatic macroinvertebrates are won from different types of water bodies of different ecological conditions (see e.g. Ehlert et al., 2002). As a side effect, a surplus of these monitoring is growing knowledge and understanding on species biogeography and taxonomy, potentially. It is timeconsuming to recover this treasure, and financial support for this and highly qualified work is very rare. However, the evaluation of these data promises improvement of indicator powers and quality of assessments.

In other countries (e.g. The Netherlands, Austria) the midge larvae are integrated in the assessment routines. In Germany, however, they are included only on tribe level, to date. Thus, the knowledge of biogeographic the distribution of species is relatively restricted. Up to now, a comprehensive overview of the chironomid fauna is published only for the Land of Brandenburg, based on the monitoring activities of the last decade (Orendt et al., 2014). The authors found an enormous increase of species records from ca. 40 to 408 with a valid species status within few years representing $56 \%$ of the species and $73 \%$ of the genera of the German chironomida fauna. Basic analysis of species distributions in regional water body types found each water body type as an individual. Further analysis was required (Orendt et al., 2014).

In this paper, the distribution and preferences of chironomids along a degradation gradient are investigated. Earlier, Marzali et al. (2010) elaborated indicators for ecological status of streams independent from morphological conditions. A series of references address the relations between chironomid communities and their response to environmental factors and pollution mostly using multivariate methods (Armitage and Blackburn, 1985; Campbell et al., 2009; Mauad et al., 2017; Odume et al., 2015; Özkan et al., 2010; Popović et al., 2016). Here, however, taxa occurrences in degradations along a five-level gradient in several water body types are studied, but not their relations to single measured environmental factors as done e.g. by Ehlert $e t$ $a l$. (2002) and in the papers mentioned. These types are classified a priori by unimpacted conditions, and serve as a reference in bio-assessment for the implementation of the European Water Framework Directive (European Commission, 2000). The environmental gradient used here is the degradation inferred by the non-chironomid 
macro-invertebrate taxa deriving from the monitoring as mentioned above.

Considering this, the study presented here undertakes an analysis to follow the questions i) whether the distribution of chironomid taxa can be explained better by the water body types (or groups of them) or by levels of degradation (i.e. quality classes), and ii) whether the distribution of the chironomids reflects the classification of the water body types specified and their degradation levels. The results should help to evaluate the ecological preferences of the taxa known so far (e.g. from Moller Pillot, 1984a, 1984b, 2009, 2013; Moller Pillot and Buskens, 1990) and to revise their qualifications as indicators in water assessments ( $e$ g. indices like in Moog and Hartmann, 2017).

\section{AREA AND WATER BODIES INVESTIGATED}

The Land of Brandenburg covers a part of the "Central European lowlands" with few places rising above $100 \mathrm{~m}$ asl. The sites sampled during the monitoring was situated in all parts of the region (see a map in Orendt et al., 2014). 85\% of the sites were sampled at least two and mostly three or more times. Sampling season was spring, in most cases. Some samples were taken in autumn, which is also accepted by the rules of the protocol (Meier et al., 2018), but not summer time, as the assessments results are biased by the absence of the emerged species providing for wrong results. Also Koperski (2009) found seasonal effects as a strong factor for differences in the taxonomic composition of a sample site.

The sites represented 11 running water types (Tab. 1) following the definition by Meier et al. (2018) and differing in their ecological status in five levels ('high', 'good', 'moderate', 'poor', 'bad') as specified by the EU-Water Framework Directive classification (European Commission, 2000) (Tab. 1). This Directive requires 'good' quality for all water bodies of certain meaning referring to chemical, biological, and morphological criteria based on reference conditions of water body types. These conditions can be inferred as described by Hawkins and Vinson (2000) or, following closer to the Water Framework Directive, by Ehlert et al. (2002) and Sanchéz-Montoya et al. (2007) resulting in water body types and characteristic communities for each of these types. Furthermore, the Directive requires to assess the quality class for a water body respected. For water bodies with a status less than 'good', measures have to be undertaken in order to improve the quality. Biological conditions are assessed using phytobenthic, macrophytic, macro-invertebrate, and fish communities. This paper refers only to running water types and assessments deriving from macro-invertebrate communities. In the data used here, samples from the same sites differed in their ecological status, in some cases.

Tab. 1. Running water types (according to Meier et al., 2018) represented in the samples and ecological status (according to the Directive 2000/60/EC, European Commission, 2000) of the samples/sample sites investigated in the monitoring from 2004 to 2013 and number of samples $(\mathrm{N})$.

\begin{tabular}{|c|c|c|}
\hline Water body type code & Definition & $\mathbf{N}$ \\
\hline Type 11 & Small organic substrate-dominated rivers & 291 \\
\hline Type 12 & Mid-sized and large organic substrate-dominated rivers & 204 \\
\hline Type 14 & Small sand-dominated lowland rivers & 369 \\
\hline Type 15 & Mid-sized sand and loam-dominated lowland rivers & 264 \\
\hline Type $15 \mathrm{~g}$ & Large sand and loam-dominated lowland rivers & 117 \\
\hline Type 16 & Small gravel-dominated lowland rivers & 35 \\
\hline Type 17 & Mid-sized and large gravel-dominated lowland rivers & 16 \\
\hline Type 19 & Small streams in riverine floodplains & 290 \\
\hline Type 20 & Very large sand-dominated rivers & 116 \\
\hline Type 21 & Lake outflows & 236 \\
\hline Type '0' & Heavily modified water bodies & 417 \\
\hline not classified & - & 13 \\
\hline \multicolumn{3}{|c|}{ Ecological status of the samples/sample sites } \\
\hline & High & 6 \\
\hline & Good & 389 \\
\hline & Moderate & 651 \\
\hline & Poor & 828 \\
\hline & $\mathrm{Bad}$ & 480 \\
\hline & Unknown & 14 \\
\hline
\end{tabular}




\section{METHODS}

\section{Data sources}

The data used here derived from the macro-invertebrate database of the Land Brandenburg (Environmental Agency, LfU, Potsdam) obtained during 2004 to 2013 from monitoring. Generally, the data include larvae, pupae, pupal exuviae, and adults obtained from sampling procedures according to the standard procedure (Meier et al., 2018) for assessment according to Water Framework Directive. The procedure requires sampling from all present habitats of a site in quantitative relation to the share of their coverage resulting in a mixed sample of 20 subsamples. As a total, this should cover $1.25 \mathrm{~m}^{2}$ surface over a stretch length of $50 \mathrm{~m}$. Abundances were re-calculated to individuals $\mathrm{m}^{-2}$. A minimum of 350 individuals (in Brandenburg 500) out of at least $1 / 6$ of the whole sample were sorted and counted and the taxa identified. In the general standard, however, chironomids are respected only on tribe level, but the routines in Brandenburg require identification as precise as possible. In addition, adults were collected from the riparian vegetation, in some years. The database held records from 2396 samples at 896 sites from 201 water courses. Most of the material comprised larvae. The data concerning the ecological status of the sampled water bodies derived from assessments based on the whole macro-invertebrate communities (for classes, see Tab. 1). Lower ecological status derives mostly from morphological degradation of the water body sampled. The identifications are reliable, as all collegues involved had considerable experience with all developmental stages: Claus Orendt, Leipzig, ClausJoachim Otto, Fahrenkrug, Berthold Janecek, Vienna, Xavier-Francois Garcia, Berlin, and Susanne Michiels, Emmendingen. Records were extracted from the database according to the taxonomic level identified. Nomenclature was revised referring to the recent version of the online database in Fauna Europaea (Sæther and Spies, 2013) and Spies and Sæther (2004), in which also all synonyms are listed and which has the highest priority in questions of nomenclature.

\section{Data processing}

The records of taxa in a sample were available in counts, or densities (individuals $\mathrm{m}^{-2}$ ) or presence/absence. For two reasons, all data were transformed in presence/absence in each sample: i) it was not possible to equalize the different sorts of abundances, and ii) high variations of original abundances or densities of the taxa in the samples tend to bias the constancy of a taxon in a water body type or a degradation class and may not support to follow the aim of the study. The data from adults and pupal exuviae were omitted as they were not collected consistently and, therefore, provided only scattered information leaving only larvae and pupae for further processing. The data (frequencies) from each sample were summarized for the different quality classes (Tab. 1) of each running water type leaving 46 variables (e.g. 'type 11_high', type 11_good', etc.). In type 11 and type 14, some data in 'high' quality states were available (Tab. 1). From the other types, communities from only lower states were sampled. Then, in order to reduce statistical noise, dominant and evenly distributed (present in $>39$ variables), and rare (present in $<3$ variables) taxa were eliminated and species with similar ecological preferences summarized (e.g. Endochironomus tendens and E. albipennis summarized to Endochironomus sp., or all species of Ablabesmyia) leaving 250 taxa for the further analysis out of 432 taxa recorded altogether. To analyse the distribution of the taxa in certain quality classes in the water body types (from 'high' to 'bad'), a detrended correspondence analysis ('DCA'; Hammer, 2012) was performed. For this, the relative frequencies of the taxa in the different quality classes of each running water type were used, but not the original data values of densities. This transformation mirrors the shares of the taxa in the community and makes the part of a taxon better comparable between the sites than the original counts or frequencies. In a test run, an evaluation using original frequencies did not show substantial differences in the results, so the more realistic data were used further on. To study and show the pattern of degradation gradient in each water body type, the quality classes from 'high' to 'bad' were plotted against the scores of the first axis of the DCA. For relations of taxa along the gradient, their DCA scores ( $1^{\text {st }}$ axis) were correlated with the frequencies of each taxon and tested for significance using Spearman's rank correlation coefficient.

For the general distribution of taxa in quality classes, regardless of water body type, the frequencies in the different quality classes from all samples were summarized (see Annex 1).

\section{RESULTS}

\section{Water body types and degradation classes}

The species richness as a simple community descriptor indicated an increase from 'good' to 'poor' conditions, apparently, and then a drop to 'bad' conditions. However, due to inconsistent response in the different types, these differences were not statistically significant, except for the difference between 'poor' or 'moderate' and 'bad' conditions, respectively $(\mathrm{p}<0.05$; Wilcoxon test; values from waters of 'high' were neglected, here, due to the restricted number of data).

The DCA revealed that the distribution of the taxa was determined by quality classes, on one hand, and to water body types, on the other hand. This is illustrated in Fig. 1 
broken down in two different views. In Fig. 1 (left panel), the data points of each quality state are marked with the same colour of hulls and symbols indicating a gradual shift from 'bad' to 'good' in half-right upwards direction. Only the points for the 'high' states do not follow this shift pattern. In Fig. 1 (right panel), the data points of each water body type are marked with the same colour and symbols. In this view, also a shift in diagonal direction appears, but shows simply a clear separation of certain water body types from one and another, as no gradient was measured. The longish shape of most of the types is due to the shift direction from 'bad' to 'good' observed from the view in Fig. 1 (left panel). The first axis counts for $20.8 \%$ of the total variance and is much stronger than the $2^{\text {nd }}(7.4 \%)$ and following axes. A plot of the scores from the $1^{\text {st }}$ axis along the degradation classes (Fig. 2) illustrates that the chironomid communities reflect in many, but not in all water body types a gradient from higher to lower quality classes. Particularly in type 11, 14, and 21, the decline is not continuous. Also, the only data points for 'high' quality status in types 11 and 14 do not follow the general pattern.

To examine whether a grouping of some water body types makes the results more significant, a DCA was performed with only 'good' and 'high' sites. However, neither the grouping of types in proximity nor an additional grouping of small and large water body types tried arbitrarily were able to consolidate or refine the distribution patterns of the taxa in degradation levels.

\section{Species preferences}

The correlation of the frequencies of the taxa with the scores from the DCA 1st axis resulted in a list of stronger and weaker indicators in the gradient (Tab. 2). Generally strong preferrers of 'worse' conditions in these water body types were e.g. Endochironomus sp., Glyptotendipes pallens, Polypedilum pedestre, G. paripes. Strong preferrers of 'moderate' or 'better' conditions were $e . g$. Brillia sp., Tvetenia discoloripes/verralli, Prodiamesa olivacea, Micropsectra notescens gr., Polypedilum cultellatum. However, the preferences were not consistent for each water body type (Fig. 3). This corresponds to the results from above (Fig. 2).

Some taxa with the highest correlations shall be presented as examples, here (Fig. 3). G. pallens was mostly found in 'poor' and 'bad' water bodies in type 12 (Midsized and large organic substrate-dominated rivers), whereas in type 20 (Very large sand dominated rivers) the species is more evenly frequent in water bodies of all degradation classes (similar to Endochironomus sp.). As a preferrer of better conditions, Tvetenia discoloripes/verralli is most frequent in water bodies of 'good' quality but only in type 11 (Small organic substrate-dominated rivers), obviously. Prodiamesa olivacea and Paratrissocladius excerptus (no chart) were found most frequent in water bodies of 'good' quality only in type 14 (Small sanddominated lowland rivers), whereas P. olivacea appeared with no greater differentiation in the other types, and $P$. excerptus in type 11 (Small organic substrate-dominated
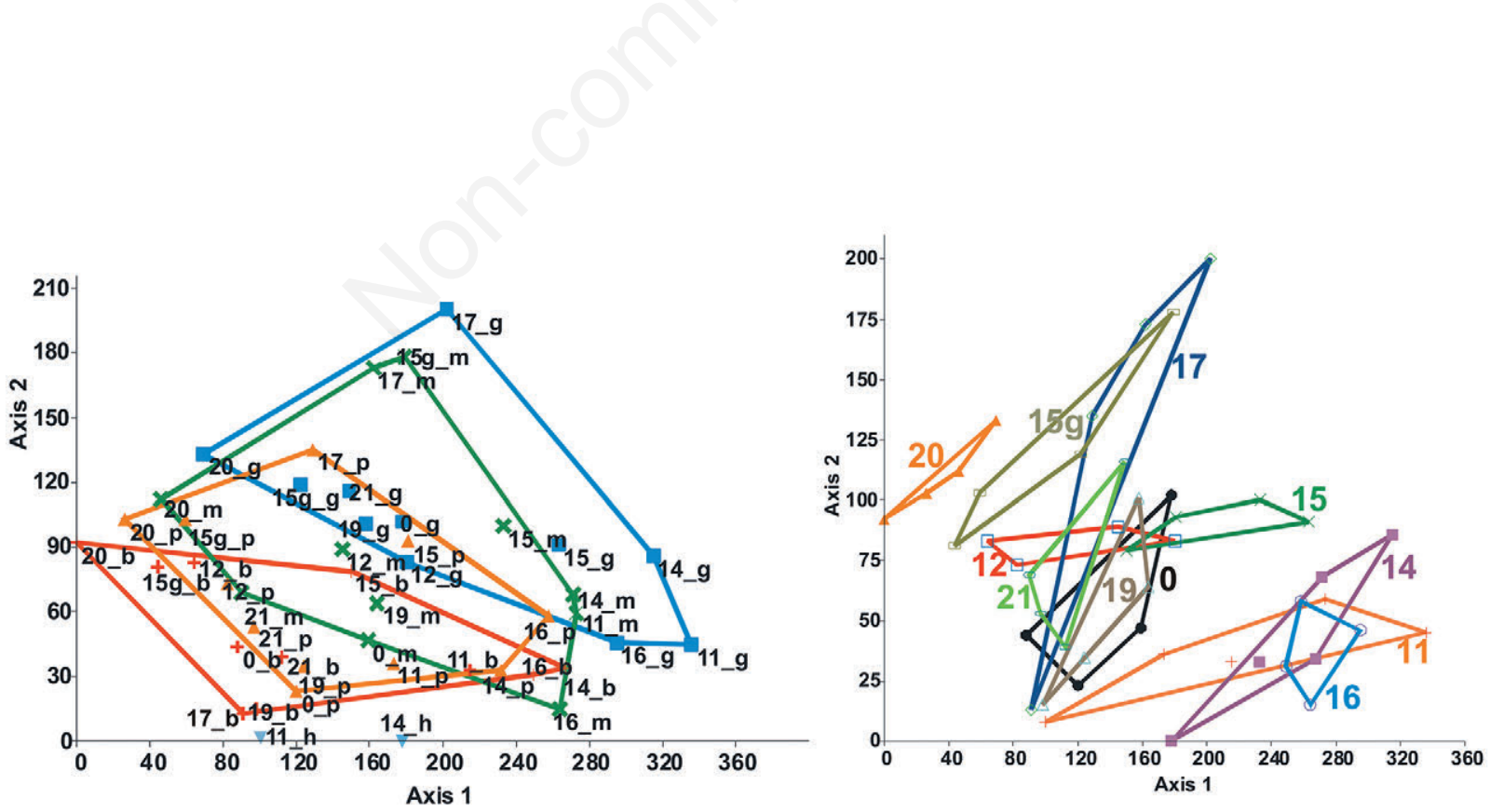

Fig. 1. Plot of the axis scores from the DCA (axis 1: 20.76\% of total variance, Eigenvalue 0.3136; axis 2: 7.39\%, Eigenvalue 0.1116; axis 3: 3.14\%, Eigenvalue 0.0478). Left panel: colours of the hulls represent the same degradation level in the water body types (red, bad; orange, poor; green, moderate; dark blue, good; light blue, high. Right panel: colours of the hulls represent the same water body type (definitions for the representing numbers: see Tab. 1). 
rivers), more frequent under 'worse' conditions. Only few species were recorded to prefer distinctly 'moderate' or 'poor' water bodies. Conchapelopia sp. was statistically strongly correlated with 'moderate' conditions, no matter of water body type, but also with not much lower frequencies than in the adjacent quality classes of some types. This suggests Conchapelopia sp. to be a more general indicator of quality not restricted to a certain type, in opposite to the taxa mentioned above. Preferrers of 'poor' conditions were Polypedilum pedestre with higher frequencies in type 12, but evenly abundant in type 20, and Clinotanypus nervosus (no chart). However, the correlation with the gradient was weak (-0.204; not significant).

A reduction of the taxonomic level to genus was also tested. The result of the scatter diagram was similar to the plot with higher taxonomic levels (Fig. 1). However, the gradient in the data was much less striking (Axis 1: 12.694 $\%$ of total variation; axis 2: $11.234 \%$; axis $3: 9.761$ ) indicated also in a missing distinctive gradient pattern like in Fig. 2. Moreover, correlations were much lower and only very few of statistical significance.

\section{Use for practice}

The sum of all frequencies of each taxon in each quality class, regardless in which water body type it occurred (Tab. S1), provides a comprehensive overview of strong and weak indicators of conditions. Vertical sorting the frequencies of the single taxa distributed in the quality classes illustrates the species shift from 'high' to 'bad' conditions.
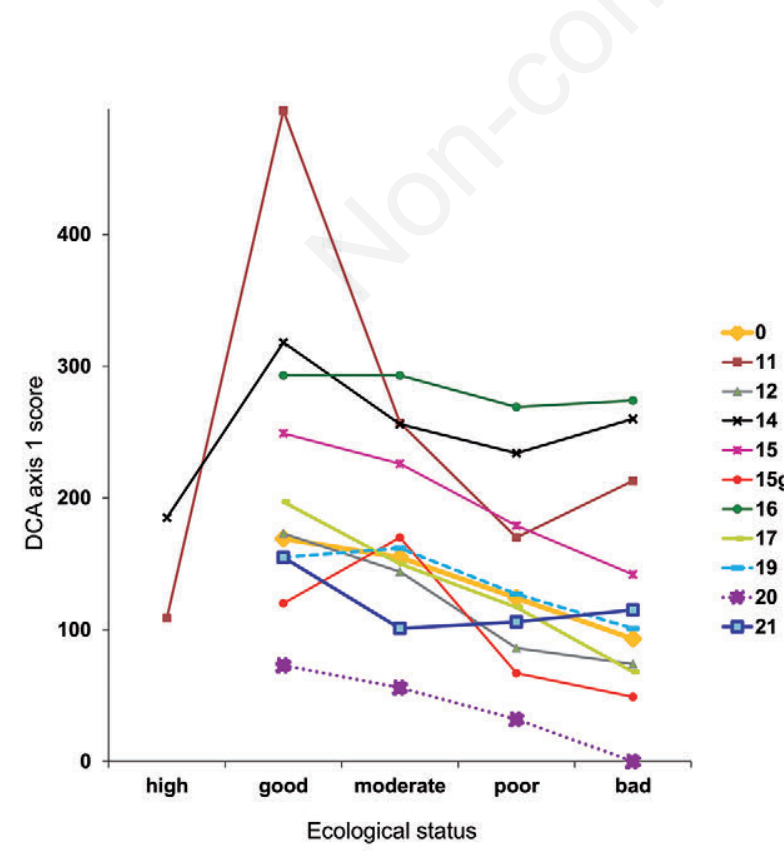

Fig. 2. Plot of the scores from the 1 st axis in the degradation classes of the water body types. For definitions of the representing numbers: see Tab. 1.

\section{DISCUSSION}

The approach of these first evaluations of the database studied the distribution of chironomids along a gradient. This gradient is represented by five levels derived from bio-assessment based on macro-invertebrates including chironomids only on tribe level. In opposite to many others studies, which address the relation between communities and environmental factors, no ecological types as references should be inferred, here (as performed

Tab. 2. Correlation of chironomid taxa frequencies with score of the DCA axis 1 (Spearman rank correlation). The list is restricted to taxa with a coefficient $>0.5$. Positive coefficients $(\mathrm{rS})$ indicate a preference for better, negative for worse conditions. P, level of significance. The full list is provided as Tab. S2.

\begin{tabular}{|c|c|c|}
\hline Taxon & $\mathrm{r}_{\mathrm{S}}$ & $\mathbf{P}<$ \\
\hline Brillia sp. & 0.9086 & 0.001 \\
\hline Polypedilum pedestre & -0.8444 & 0.001 \\
\hline Endochironomus sp. & -0.8395 & 0.001 \\
\hline Glyptotendipes pallens & -0.8140 & 0.001 \\
\hline Tvetenia discoloripes/verralli & 0.7827 & 0.001 \\
\hline Glyptotendipes paripes & -0.7650 & 0.001 \\
\hline Dicrotendipes nervosus & -0.7318 & 0.001 \\
\hline Cricotopus (Isocladius) sp. & -0.6683 & 0.001 \\
\hline Paratrissocladius excerptus & 0.6635 & 0.001 \\
\hline Apsectrotanypus trifascipennis & 0.6625 & 0.001 \\
\hline Xenochironomus xenolabis & -0.6558 & 0.001 \\
\hline Cladopelma viridulum & -0.6343 & 0.001 \\
\hline Cricotopus (Cricotopus) sp. & -0.6179 & 0.001 \\
\hline Parachironomus gracilior gr. & -0.6171 & 0.001 \\
\hline Micropsectra notescens gr. & 0.6148 & 0.001 \\
\hline Tanytarsus mendax & -0.6120 & 0.001 \\
\hline Glyptotendipes sp. & -0.6095 & 0.001 \\
\hline Cricotopus intersectus & -0.6081 & 0.001 \\
\hline Polypedilum cultellatum & 0.6074 & 0.001 \\
\hline Cricotopus sylvestris gr. & -0.5911 & 0.001 \\
\hline Tanypus kraatzi & -0.5810 & 0.001 \\
\hline Paratanytarsus inopertus & -0.5715 & 0.001 \\
\hline Eukiefferiella $\mathrm{sp}$. & 0.5687 & 0.001 \\
\hline Chironomus plumosus gr. & -0.5569 & 0.001 \\
\hline Parametriocnemus stylatus & 0.5549 & 0.001 \\
\hline Rheotanytarsus curtistylus & 0.5485 & 0.001 \\
\hline Chironomus luridus gr. & -0.5417 & 0.001 \\
\hline Procladius choreus & -0.5352 & 0.001 \\
\hline Rheocricotopus sp. & 0.5287 & 0.001 \\
\hline Paratanytarsus dissimilis gr. & -0.5154 & 0.001 \\
\hline Rheocricotopus fuscipes & 0.5051 & 0.001 \\
\hline Tanytarsus usmaensis & -0.5003 & 0.001 \\
\hline
\end{tabular}


e.g. in Ehlert et al., 2002, Sanchéz-Montoya et al., 2007, Hawkins and Vinson, 2000). This investigation focussed on the adoption of chironomids on a precise taxonomic level for an existing assessment system based on ecological types elaborated earlier. The results show that the distribution of the chironomids follow to a greater part the a priori classification given by the non-chironomid macro-invertebrates.
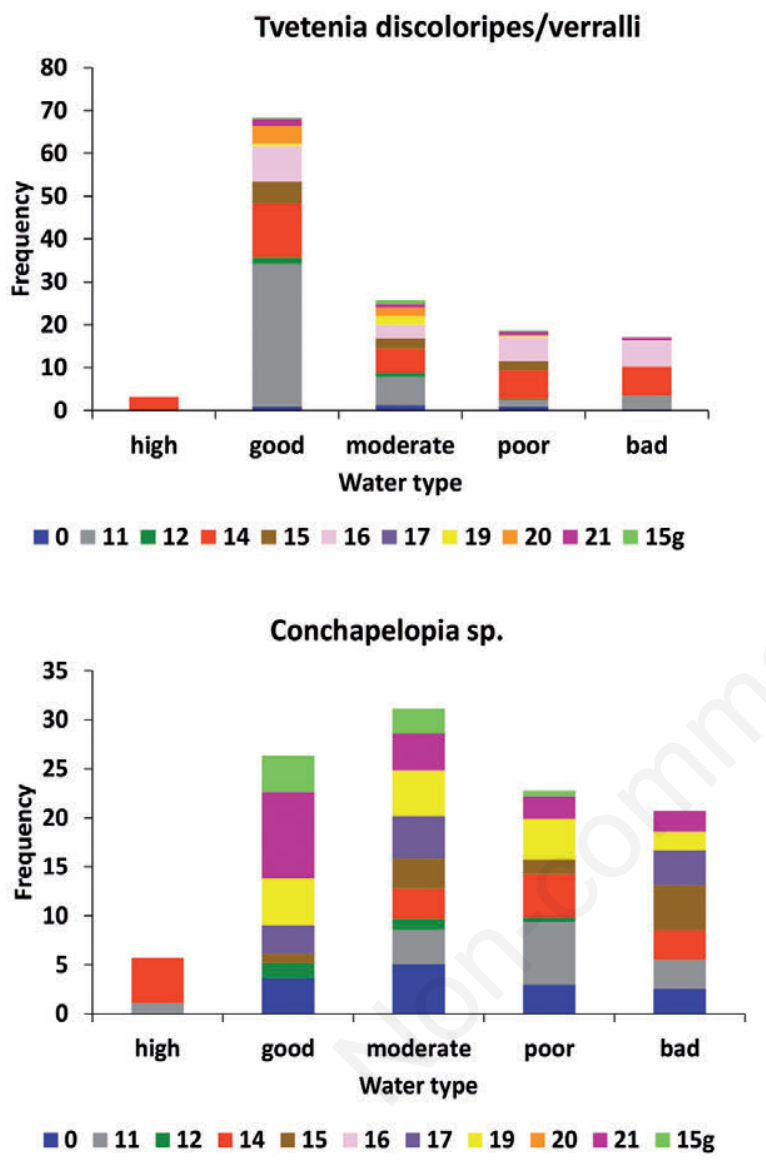

Endochironomus sp.

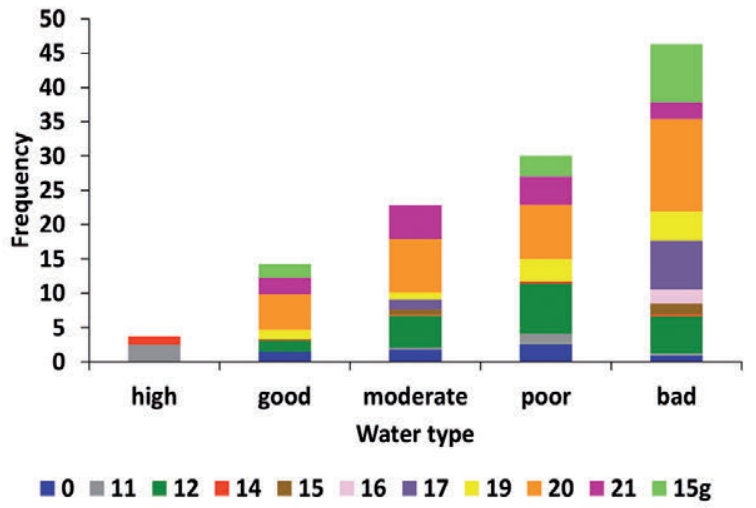

The DCA revealed that the distribution of the taxa is determined by both, water body type and degradation, however, with different patterns. On the one hand, the water body types segregate from each other, in some cases clearly, regardless of their ecological quality status. The diagonal distribution of the water body types in the plot may suggest a gradient following a certain environmental factor not measured, here. Indeed, in the left part of the chart, the

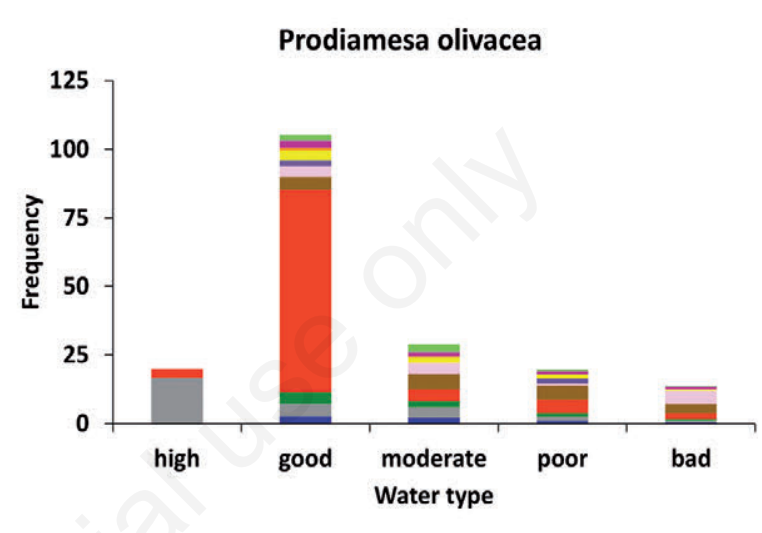

$\square 0=11=12 \square 14=15=16 \square 17=19 \square 20 \square 21=15 g$

Polypedilum pedestre

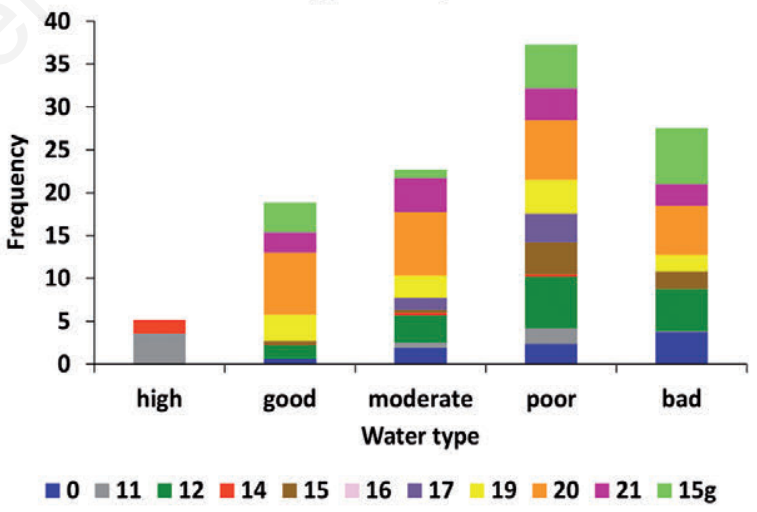

Glyptotendipes pallens

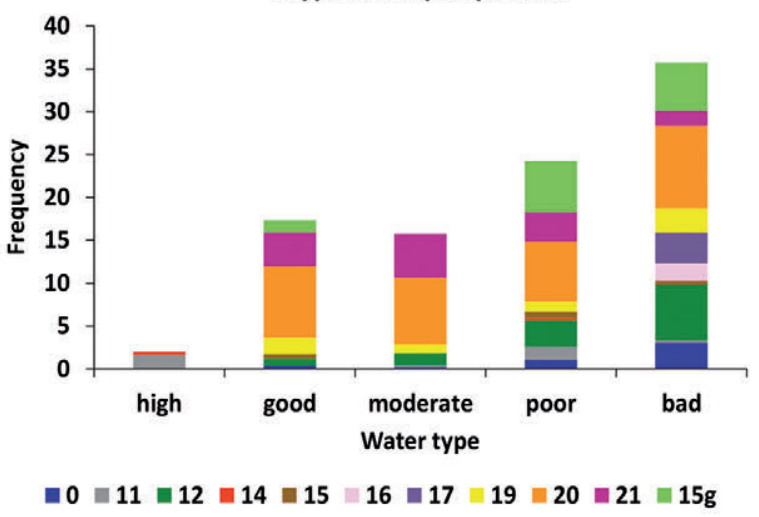

Fig. 3. Frequencies of selected taxa broken down to their occurrences in the water body types and the quality classes. 
points for two larger water bodies (Large sand and loamdominated lowland rivers, and Very large sand-dominated rivers) are located, but elsewhere other large waters are mixed with smaller ones, so that it is not convincing to consider water body size as a driving force. It may be possible to find such a factor in a single parameter used while establishing the water body typology (Lorenz et al., 2004), but this is not analysed, here.

On the other hand, the plots showed a shift of communities within a degradation gradient indicating a second driving force for the taxa distribution. This suggests chironomids to react in a similar direction like other macro-invertebrates, from which the data of the water qualities were derived.

The constant drift of community with declining water body quality (Fig. 2) was the rule for most of the water body types included here indicating a constant decreasing quality. However, in some other water body types, the taxon distributions changed probably under non-constant conditions along the degradation gradient due to discontinuous change or loss of typical habitats in certain degradation levels (e.g. from 'poor' to 'bad' in type 11). The loss of habitat types under degradation conditions and the consequences for a correct assessment was investigated by Marziali et al. (2010) or Odume et al. (2015). From both studies can be concluded that problems in assessment of degradation may occur, when communities are not sampled from the same habitat along a pollution gradient due to loss or temporal absence.

In type 21 (Lake outflows) and type 16 (Small graveldominated lowland rivers), the changes of communities seemed to be small. In both types with data from 'high' status, the starting point seems to be very far from the next quality level. However, as only 6 water bodies were sampled, these data are not reliable, and the scale for taxa preferences remains restricted to the range from 'good' to 'bad', so far. In following studies, more data from more samples of 'high' quality waters are desirable, if available. However, this should be respected and tested later, as the goal of this paper was to investigate general patterns and tendencies of ecological distribution.

Breaking down the distribution in the quality classes to each water body type revealed taxa preferences i) only in certain water body types, or ii) general preferences regardless of water body type (e.g. Conchapelopia sp.). In the first case, the preferences are of importance for the validation only for the respected water body type(s). In the second case, the taxa of concern are candidates for general bio-indication, no matter in what water body it is sampled. When the results are used for validating the indicator values, this has to be respected. Summing up all frequencies of each taxon in each quality class regardless in which water body type it occurred (sorted list, Tab. S1) makes the preferences ready for further statistical evaluation. The results can be used, in general, for evaluating existing indices and preferences or for elaborating indices and weights of powerful indicator taxa for classifications or revisions. However, before implementing the results have to be discussed (referring to indicator classifications from other countries, e.g. Janecek et al., 2017a and references therein) or tested for plausibility before use.

The reduction of taxonomic level to genus may be useful for special questions and help to facilitate the work in practice. The results followed the general trends based on more precise resolution, but were much less significant. This corresponds to the findings by Greffard et al. (2011). But the authors concluded that the highest taxonomic level is recommended for more precise and detailed information on environmental condition. However, this should be studied more in detail and very carefully. In those genera, which comprise species of similar ecological preferences, this may be justified (e.g. Endochironomus), while in others, the differences are remarkable (Polypedilum pedestre prefers worse conditions, in opposite to $P$. cultellatum, which was more frequent in higher quality classes).

\section{CONCLUSIONS}

The analysis of the chironomid taxa records from the European central lowland region in Brandenburg showed that the distribution of the taxa is driven by their occurrences in i) water body types and ii) quality classes. The results can be used for validation and establishing specific indicator values for bio-assessment. However, some taxa showed clear quality preferences only in some water body types. This allows the classification of a series of taxa according their preferences and opens the insect group for a broader and useful application in degradation assessment than used now in many protocols. Especially in water bodies, from which only a too small number of species and individuals of non-chironomid macroinvertebrates are collected for a reliable assessment, midge larvae and pupae can provide for robust results. However, further studies should be performed to elucidate the indication power of the taxa in the water body types considered here. The next step for practical using the results from this study should be to compare the findings of the taxa's preferences with expert knowledge and references in the literature, and so, enhance both the power and usefulness of indication and quality of assessment systems.

\section{ACKNOWLEDGEMENTS}

I am greatly indebted to Jörg Schönfelder and Dirk Langner from the Brandenburg Agency of Environment in Potsdam, who were responsible for the monitoring 
programme and the management of the database. Many thanks for their co-operation and the supply of the data. Thanks also to two unknown reviewers for their thorough examinations and useful comments to improve the manuscript.

\section{REFERENCES}

Armitage PD, Blackburn JH, 1985. Chironomidae in a Pennine stream system receiving mine drainage and organic enrichment. Hydrobiologia 121:165-172.

Campbell BD, Haro RJ, Richardson WB, 2009. Effects of agricultural land use on chironomid communities: Comparisons among natural wetlands and farm ponds. Wetlands 29:1070-1080.

Ehlert T, Hering D, Koenzen U, Pottgiesser T, Schuhmacher H, Friedrich G, 2002. Typology and type specific reference conditions for medium-sized and large rivers in North RhineWestphalia: Methodical and biological aspects. Internat. Rev. Hydrobiol. 87:151-163.

European Commission, 2000. Directive 2000/60/EC of the European Parliament and of the Council of 23 October 2000 establishing a framework for Community action in the field Response of macro-invertebrates to river pollution 13 of water policy. Amended by Decision No 2455/2001/EC, Directive 2008/32/EC. https://eur-lex.europa.eu/legal-content/EN/TXT/? uri=CELEX:32000L0060.

Greffard MH, Saulnier-Talbot E, Gregory-Eaves I, 2011. A comparative analysis of fine versus coarse taxonomic resolution in benthic chironomid community analyses. Ecol. Indicat. 11:1541-1551.

Hammer Ø, 2012. PAST. Palaeontological Statistics. Ver. 2.17. Available from: http://folk.uio.no/ohammer/past

Janecek B, Moog O, Moritz C, Orendt C, Saxl R, 2017a. Diptera: Chironomidae: Orthocladiinae. In: O. Moog and A. Hartmann (eds.), Fauna Aquatica Austriaca. Ministry of Agriculture, Vienna.

Janecek B, Moog O, Orendt C, 2017b. Diptera: Tanypodinae. In: O. Moog and A. Hartmann (eds.), Fauna Aquatica Austriaca. Ministry of Agriculture, Vienna.

Janecek B, Moog O, Orendt C, 2017c. Diptera: Prodiamesinae In: O. Moog and A. Hartmann (eds.), Fauna Aquatica Austriaca. Ministry of Agriculture, Vienna.

Janecek B, Moog O, Orendt C, 2017d. Diptera: Chironomidae: Podonominae, Buchonomyiinae. In: O. Moog and A. Hartmann (eds.), Fauna Aquatica Austriaca. Ministry of Agriculture, Vienna.

Janecek B, Moritz C, Orendt C, Saxl R, 2017e. Diptera: Chironomidae: Diamesinae. In: O. Moog and A. Hartmann (eds.), Fauna Aquatica Austriaca. Ministry of Agriculture, Vienna.

Janecek B, Orendt C, Contreras-Lichtenberg R, 2017f. Diptera: Chironomidae: Chironominae. In: O. Moog and A. Hartmann (eds.), Fauna Aquatica Austriaca. Ministry of Agriculture, Vienna.

Koperski P, 2009. Reduced diversity and stability of chironomid assemblages (Chironomidae, Diptera) as the effect of moderate stream degradation. Pol. J. Ecol. 57:125-138.

Lorenz A, Feld CK, Hering D, 2004. Typology of streams in Germany based on benthic invertebrates: Ecoregions, zonation, geology and substrate. Limnologica 34:390-397.

Marziali L, Armanini DG, Cazzola M, Erba S, Toppi E, Buffagni A, Rossaro B, 2010. Responses of chironomid larvae (Insecta,
Diptera) to ecological quality in mediterranean river mesohabitats (South Italy). River Res. Applic. 26:1036-1051.

Mauad M, Siri A, Donato M, 2017. Does type of substratum affects chironomid larvae assemblage composition? A study in a river catchment in northern Patagonia, Argentina. Neotrop. Entomol. 46:18-28.

Meier C, Böhmer J, Rolauffs P, Hering D, 2018. Kurzdarstellungen "Bewertung Makrozoobenthos" and "Core Metrics Makrozoobenthos", ver. June 2006. Availabel from: http://www.fliessgewaesserbewertung.de/downloads/Kurzdar stellung_Bewertung_MZB_Mai2011.zip.

Moller Pillot HKM, Buskens RFM, 1990. [De larven der Nederlandse Chironomidae (Diptera). Deel C: Autoekologie en verspreiding].[Book in Dutch]. Nederlandse Faunistische Mededelingen 1C. Leiden: $86 \mathrm{pp}$.

Moller Pillot HKM, 1984a. [De larven der Nederlandse Chironomidae (Diptera). Deel B, (Orthocladiinae sensu lato) ].[Book in Dutch]. Nederlandse Faunistische Mededelingen 1B (Stichting European Invertebrate Survey Nederland). Leiden: 175 pp.

Moller Pillot HKM, 1984b. [De larven der Nederlandse Chironomidae (Diptera). Deel A, (Inleiding, Tanypodinae and Chironomini)].[Book in Dutch]. Nederlandse Faunistische Mededelingen 1A, (Stichting European Invertebrate Survey Nederland), 3. dr. Leiden: $227 \mathrm{pp}$.

Moller Pillot HKM, 2009. Chironomidae larvae of the Netherlands and adjacent lowlands. Biology and ecology of the Chironomini. KNNV Publishing, Zeist: 270 pp.

Moller Pillot HKM, 2013. Chironomidae Larvae, Part 3 - Aquatic Orthocladiinae. Biology and Ecology of the Aquatic Orthocladiinae. KNNV Publishing, Zeist: 312 pp.

Moog O, Hartmann A, 2017. Fauna Aquatica Austriaca. Ministry of Agriculture, Vienna.

Odume ON, Palmer CG, Arimoro FO, Mensah PK, 2015. Influence of selected biotopes on chironomid-based bioassessment of the Swartkops River, Eastern Cape, South Africa. Water SA 41:343-358.

Orendt C, Otto CJ, Michiels S, Janecek BF, Garcia XF, Müller R, 2014. Faunistic overview of Chironomidae (Insecta: Diptera) in lowland running waters of north-east Germany (Brandenburg) based on 10-year EU-Water Framework Directive monitoring programme. Lauterbornia 77:37-62.

Özkan N, Moubayed-Breil J, Çamur-Elipek B, 2010. Ecological analysis of chironomid larvae (Diptera, Chironomidae) in Ergene River basin (Turkish Thrace). Turk. J. Fish. Aquat. Sci.10:93-99.

Popović NZ, Đuknić JA, Čanak Atlagić JŽ, Raković MJ, Tubić BP, Anđus SP, Momir MM, 2016. The relation between chironomid (Diptera: Chironomidae) assemblages and environmental variables: The Kolubara River case study. Arch. Biol. Sci. 68:405-415.

Sanchez-Montoya MDM, Punti T, Suarez ML, Vidal-Abarca MDR, Rieradevall M, Poquet JM, Zamora-Munoz C, Robles R, Alvarez M, Alba-Tercedor J, Toro M, Puj Ante AM, Munne A, Prat N, 2007. Concordance between ecotypes and macroinvertebrate assemblages in Mediterranean streams. Freshwater Biol. 52:2240-2255.

Sæther OA, Spies M, 2013. Fauna Europaea: Chironomidae. In: P. Beuk and T. Pape (eds.), Fauna Europaea: Diptera: Nematocera. Fauna Europaea, ver. 2.6.2. Internet database. http://www.faunaeur.org. Cited: 20 January 2018.

Spies M, Sæther OA, 2004. Notes and recommendations on taxonomy and nomenclature of Chironomidae (Diptera). Zootaxa 752: 1-90. 